\title{
TERMOIMPULSIMEETODI KASUTAMISEST PREPARATIIVSES GAASIKROMATOGRAAFIAS
}

Termoimpulsimeetodit, mis seisneb gaasikromatograafilise kolonni temperatuuri kiires ning lühiajalises tõstmises, on seni analüütilistes töödes rakendatud kolonni lahutusvõime suurendamiseks $\left[{ }^{1},{ }^{2}\right]$.

Preparatiivsel gaasikromatograafilisel segude lahutamisel osutub võimalikuks termoimpulsimeetodi abil kondensatsioonitingimusi parandada. Kui tõsta väljumisel oleva komponendi piirkonnas, s. o. kolonni lõpuosas, temperatuuri komponendi väljumise ajaks, toimub aine väljumine kolonnist kiiremini ning kontsentreeritumalt. Et saagis kondenseerimisel sõltub väljuva aine kontsentratsioonist kandegaasis [3], siis tõuseb ka saagis.

Termoimpulsimeetodit kasutati selliste preparatiivsete kolonnidega töötamisel, mille läbimõōt oli $18 \mathrm{~mm}$, pikkus $3,2 \mathrm{~m}$ või läbimõõt $33 \mathrm{~mm}$, pikkus 2,2 m. Mõlema kolonni lõpuosa oli $0,6 \mathrm{~m}$ pikkuselt eraldi köetav. Katsetel lülitati lisaküte sisse aine väljumise algul ja kütmine katkestati pärast piigi maksimumi saabumist.

Katsetulemused esitatakse tabelis.

Selgub, et saagise kasv on suurem kõrgemal kondenseerimistemperatuuril tehtud katsetes, samuti väiksema aine hulga ja suurema küttevõimsuse puhul. Meetodi rakendamine on efektiivne siis, kui antud kromatografeerimis- ja kondensatsioonitingimustel ei saada saagist üle $50 \%$.

Võrreldes analüütiliste rakendustega, komplitseerib preparatiivsete kolonnide juures termoimpulsimeetodi kasutamist aksiaalse temperatuurigradiendi kujunemine ja sellest tingitud ebaühtlane komponendi liikumiskiirus kolonni ristlōikes.

Kolonni lõpuosa kiirest soojendamisest tekkiv rōhu kasv ja temperatuuri tõus detektoris põhjustavad kataromeetri reaktsioonina tunduvat piigi kuju muutust, mistõttu osutus sobivamaks kasutada detektorina leekionisatsioondetektorit haruvoolus.

Tööst järeldub, et termoimpulsimeetodi rakendamine võib kujuneda otstarbekaks suuremahulistel automatiseeritud protsessiga

\begin{tabular}{|c|c|c|c|c|}
\hline $\begin{array}{c}\text { Aine } \\
\text { hulk, ml }\end{array}$ & 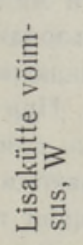 & 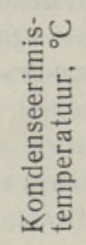 & $\begin{array}{l}\text { o̊ } \\
\frac{m}{b x} \\
\frac{\pi}{\pi} \\
\tilde{n}\end{array}$ & 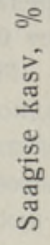 \\
\hline $\begin{array}{l}0,5 \\
0,5 \\
0,5 \\
0,5\end{array}$ & $\begin{array}{r}0 \\
480 \\
620 \\
700\end{array}$ & $\begin{array}{l}0 \\
0 \\
0 \\
0\end{array}$ & $\begin{array}{l}14 \\
17 \\
19 \\
20\end{array}$ & $\begin{array}{r}0 \\
23 \\
37 \\
44\end{array}$ \\
\hline $\begin{array}{l}0,5 \\
0,5 \\
0,5 \\
0,5\end{array}$ & $\begin{array}{r}0 \\
480 \\
620 \\
700\end{array}$ & $\begin{array}{l}-10 \\
-10 \\
-10 \\
-10\end{array}$ & $\begin{array}{l}43 \\
50 \\
54 \\
56\end{array}$ & $\begin{array}{r}0 \\
16 \\
26 \\
30\end{array}$ \\
\hline $\begin{array}{l}1,0 \\
1,0 \\
1,0 \\
1,0\end{array}$ & $\begin{array}{r}0 \\
480 \\
620 \\
700\end{array}$ & $\begin{array}{l}0 \\
0 \\
0 \\
0\end{array}$ & $\begin{array}{l}32 \\
38 \\
42 \\
44\end{array}$ & $\begin{array}{r}0 \\
20 \\
31 \\
39\end{array}$ \\
\hline $\begin{array}{l}1,0 \\
1,0 \\
1,0 \\
1,0\end{array}$ & $\begin{array}{r}0 \\
480 \\
620 \\
700\end{array}$ & $\begin{array}{l}-10 \\
-10 \\
-10 \\
-10\end{array}$ & $\begin{array}{l}55 \\
62 \\
64 \\
68\end{array}$ & $\begin{array}{r}0 \\
12 \\
17 \\
23\end{array}$ \\
\hline
\end{tabular}

Kolonn Ø $18 \mathrm{~mm}$. Termostaadi temperatuur $70^{\circ} \mathrm{C}$. Kandegaas: lämmastik mahtkiirusega $20 \mathrm{l} / \mathrm{t}$. Kromatografeeritav aine: ni-heksaan. preparatiivsetel lahutamistel, kus ülimadalate kondenseerimistemperatuuride kasutamine on raskendatud ja saagise suurus omab pōhilist tähtsust. 


\section{K I R J A N D U S}

1. Feng P. Y., Krotoszynski B. K., Nature, 188 (4748), 311 (1960).

2. Shuchowitzki A. A., Turkeltaub N. M., Fortschrittsberichte zur Gas-Chromatographie 1959, Akademie-Verlag, Berlin, 1961, S. 28.

3. Э й зе н О. Г., Л уй г а П. О., Газовая хроматография (Тр. II Всесоюзн. конф.), «Наука», М., 1964, стр. 216.

Eesti NSV Teaduste Akadeemia Küberneetika Instituut
Saabus toimetusse

17. III 1965

Э. ЛИППМАА, Ю. ПУСКАР, М. АЛЛА, А. СЮГИС

\section{ПРИМЕНЕНИЕ ДВОЙОГО ЯДЕРНОГО МАГНИТНОГО РЕЗОНАНСА СО СЛАБЫМ ВОЗМУЩАЮЩИМ ПОЛЕМ («ТИКЛИНГ») ДЛЯ УСТАНОВЛЕНИЯ ВЗАИМНОГО РАСПОЛОЖЕНИЯ УРОВНЕИ ЭНЕРГИИ СПИН-СИСТЕМЫ. I}

Для анализа спектров ЯМР, особенно при наличии сильной спин-спиновой связи в системе, очень важно знать расположение уровней энергии, т. е. установить соответствие между спектральными линиями и переходами в схеме энергетических уровней. Предложенный Фрименом и Андерсоном вариант двойного резонанса «тиклинг» ['] может быть с успехом использован для решения этой задачи.

Методика «тиклинг» заключается в воздействии на какую-либо спектральную линию радиочастотным полем $H_{2}$. При этом сила поля $H_{2}$ должна быть такой, чтобы воздействию подвергался лишь один переход. Если теперь наблюдать спектр на другой частоте $\omega_{1}$, то обнаруживаются изменения в относительных интенсивностях линий, a некоторые одиночные линии переходят в дублет $\left[{ }^{2}\right]$. При этом расщепляются лишь те линии, которые имеют общие с возмущаемым переходом энергетические уровни. Воздействуя полем $H_{2}$ последовательно на различные линии спектра, можно на основании возникающих при этом изменений в спектре построить диаграмму энергетических уровней.

Из сказанного следует, что использование методики «тиклинг» вызывает повышенные требования к аппаратуре, в частности, к стабильности постоянного поля $\mathbf{H}_{0}$ и частоты возмущающего радиочастотного поля $\mathrm{H}_{2}$, ибо необходимо, чтобы в процессе эксперимента $\omega_{2}$ не изменила своего положения относительно возмущаемой линии по крайней мере с точностью до нескольких десятых герца (стабильностьь $2 \cdot 10^{-8} /$ час).

Настоящая работа проведена на спектрометре ЯМР, созданном в секторе физики Института кибернетики Академии наук ЭССР [3]. Окончательная стабилизация частоты в этом спектрометре осуществляется с помощью спин-генератора [ $\left.{ }^{4}\right]$.

Так как вещество, дающее стабилизирующий сигнал, находится в магнитном поле, несколько отличном от поля в исследуемом образце, необходимо учитывать изменение формы линии за счет термического дрейфа магнитного поля. В связи с этим требуемая стабильность достигалась лишь после длительной работы спектрометра.

В качестве исследуемого вещества был выбран акрилонитрил, чистота которого была проверена при помощи газового хроматографа FB-4 фирмы «Шендон». Қак известно, три протона акрилонитрила образуют, следуя классификации Попла [5], систему $A B C$. Из сравнения спектров, снятых 